\title{
LA CANCILLERIA DE ENRIQUE IV, REY DE CATALUÑA (1462-1464): UNAS NOTAS
}

\author{
Josep Trenchs \\ Universidad de Valencia
}

\section{PRESENTACION}

Cataluña, a finales de 1462 , retiró, la confianza a su monarca legítimo Juan II y nombró rey y señor del Principado a Enrique IV de Castilla. El hecho y la documentación del período nos es conocida por los magníficos trabajos de Jaume Sobrequés (1).

Las causas de esta, llamémosle, desmembración de la Corona, están perfectamente resumidas en el Dietari del "Consell» barcelonés, en donde leemos:

«vehents lo Principat de Cathalunya ésser possat e constituit en tanta necessitat, oppresió e vexasió en perdició de les persones o bens dels poblats en aquella, e açó per causa del Rey D'Aragó, qui hostilment e ab gran potencia contra forma expressa de la Capitulació al dit Principat atorgade, fermade e jurade, e de altres Leys, e Libertats del dit Principal és

(1) J. SOBREQUÉS, Catálogo de la Cancilleria de Enrique IV de Castilla señor del prin. cipado de Cataluña, Barcelona, 1975. 
entreat en aquell prenent viles, castells e lochs de aquell emtant les gents, desonestant dones e donzelles, ocupant los béns e aquells donant a çaco. E encara per causa de la Lliga contra Cathalans feta per lo dit rey ab lo rey de França, en vigor de la qual gran nombre de gent francesa és intrada dins lo dit Principat prenent viles, castells e lochs de aquell, matant les gents, desonestant les dones e donzelles, occupant béns e aquells donant a çaco.

E més per causa de la renya d'Aragó, qui ensemps ab l'infant don Ferrando, llur fill, hostilment se sont mesclats ab los dits francesos, cavalcants mà armada per Empurdà, faents e executants los actes greus dessús dits, hoc mes occupants se los drets de generalitats del General, removent de fet totalment los oficials e ministres del dit General, possants et metents hi altres ministres e fahents respondre a ells dels dits drets e no servant fe promeses, ne seguretats, ne juraments, solemnament prestats de servar les dites leys e libertats.

Les quals coses e altres moltes per ells fetes contra les llibertats del dit Principat e en total destrucció de la cosa pública de aquell, per çó per los dits sguarts e altres han pensat per salvació e restauració del dit Principat e de la cosa pública de aquell, e de persones, e béns dels poblats en aquell, deurà ésser proclamat e prés e en e per senyor del dit Principat lo Serenissimo don Enrich, rey de Castella, salvats emperò los Usatges de Barcelona, Constitucions, Capitols e actes de Cort, privilegis, usos, costums e libertats generals e particulars del dit Principat e la Capitulació demunt dita en quant a aquells e aquelles han sguard al dit Principat»(2).

Desde el momento de la elección del nuevo monarca catalán, el 11 de agosto de 1462 , hasta el 24 de octubre, en que llegaron a Catalunya sus representantes, el Dietari relata los siguientes eventos:

«Lo dit sia [miercoles, l de septiembre] vench correu del senyor rey de Castella e nostro dient de paraula com no haguets letres per tant com lo camí ere perillós, com dit senyor nos havia acceptats per vassalls» (3).

(2) Manual de Novells Ardits, vulgarment apellat Dietari del Antich Consell Barceloni, vol. II, Barcelona 1893. pág. 416-17. En acta del del miercoles 11 de agosto.

(3) Id., pág. 418. 
A la mañana siguiente, los consellers y Diputados de la Generalidad catalana se dirigieron a la Catedral y se hizo procesión solemne, entonando el Te Deum laudamus, por la buena nueva (4).

El 24 de octubre «don Johan de Bemunt, lo qual en lo passat fou delliurat per aquest Principat de presó e de mà e poder del dit rey Johan, arribà en la present ciutat ensemps al Johan Ximéniz de Arévalo, batxeller, e vench de Tortosa fins ací ab les III glares sotils e II grosses e IIII naus armades, les quals la present ciutat tenia armades, e vingueren tremesos per lo senyor rey de Castella ab tot poder» (5).

Tres días después, el 27, ambos enviados visitaron en Consell municipal y mostraron a los consellers una "letra de crehensa" y otra «letre forme de potestat» del dicho rey castellano (6).

Por último, el 10 de noviembre, Juan de Beaumont, juró los privilegios de Cataluña en nombre del nuevo monarca y fue nombrado su procurador general en el Principado (7).

Su gestión al frente del gobierno catalán duró un año, pues viendo los del principado la poca ayuda obtenida de Castilla, sustituyeron a este monarca por el infante don Pedro de Portugal (8). Ante el nuevo giro político, Juan de Beaumont dimitió el 15 de enero de 1465 (9) abandonando el Principado y, seis días después, el nuevo monarca entró en Cataluña (10).

\section{LA CANCILLERIA CATALANA DE ENRIQUE IV}

La composición de la Cancillería, en cuanto a cargos y fun-

(4) Ibid. «Lo dit dia los honorables Conseliers e diputats tots foren a la Seu, e fou feta professo cantant Te Deum laudamus per la dita nova"

(5) Id., pág. 420.

(6) Ibid.

(7) Id., pág. 421: «Lo dit dia se tench Consell de C Jurats en lo qual se llegiren certs capitols qui eren stats fermats per los dits Johan de Beaumunt e Johan Ximenis, com a procura dors del senyor Rey de Castella e nostro, e per los deputats e consell llur los quals per lo consell de Cent foren loats, e no res many foren elets en sindichs de la ciutat per prestar la fealtat als dits procuradors rebent aquella en nom del dit senyor Rey los quals foren los seguents..."

(8) Id., págs. 441-443.

(9) Id., pág. 443. "Lo dit dia lo senyor don Johan de Bemunt qui regia com a loctinent re. nuncia a la dita loctinencia”.

(10) Ibid. «E res menys lo dit dia vers la VIII hores de nit lo senyor Rey en Pere net del comte D'Urgell, intrá e fonch junt a la plaga de la mar ab les galees d'en Raphel Julià. La serimonia de la qual venguda es largament continuada en libre quart de solemnitats». 
ciones, no varía de la ya vigente con la casa de Trastamara (11). Solo cambian los detentores de los oficios. Así, el 13 de noviembre de 1462 , los lugartenientes reales revocan de todos sus cargos a los oficiales de la cancillería de Juan II y así lo hacen pregonar (12). Para acceder de nuevo a los mismos será necesaria una provisión particular en cada caso (13).

a) Consejo real

A lo largo del casi año y cuarto del gobierno del lugarteniente de Enrique IV de Castilla, Juan de Beaumont, fueron consejeros los siguientes personajes:

1. Cosme MONTSERRAT, obispo de Vic, canciller (14).

2. Gaspar VILANA, vicecanciller (15).

3. Damià MONTSERRAT, juez de la Audiencia (16).

4. Guillem de SETANTI, tesorero (17).

5. Francesc DESVALL, maestre racional (18).

6. Joan ROS, abogado del fisco (19).

7. Lluis de SARRIERA, doctor en Leyes (20).

8. Francesc de PINOS, almirante (21).

9. Gerau de GUARDIOLA, doctor en Leyes (22).

10. Antoni FIGUERAS, doctor en Leyes (23).

11. Joan COPONS, doctor, caballero (24).

12. Mateu CASES (25).

13. Pere de TOROElla (26).

(11) F. SEVILlano, La Cancillería de Fernando I de Antequera, Alfonso $V$, en «AHDE» XXXVI (1965) pp. 169-216.

(12) J. SOBREQUÉS, docs. 2 y 3.

(13) Id., doc. 4 y otros.

(14) A.M. ARAGo-J-TRENCHS, Las cancillerias de la Corona de Aragón desde Jaime I a la muerte de Juan II (en prensa).

(15) J. SOBREQUÉS, docs. 91 y 586.

(16) Id., docs. 636, 2013.15.

(17) Id., 326, 394, 625, 771, 873, 937, 1115, 1154, 1211, 1220, 1398, 1424, 1546-7, 1558, $1615,1689,1750,1946,1952,1955,2169,2296,2309$.

(18) Id., doc. 431 y 2173.

(19) Id., docs., 2266 y 2309

(20) Id., doc. 504.

(21) Id., docs. $423,571,794,848,849,1005,1014,1182,1400,1445,1550,1618,1650$ y 1751 .

(22) Id., doc. 2002-3.

(23) Id., docs. 1003 y 2202

(24) Id., docs. 158, 231, 335, 390, 437, 826, 1207, 1954 y 2037.

(25) Id., 1968.

(26) Id., 635, 806, 884, 1052, 1073, 1191, 1243, 1320 y 1368. 
14. Ramón de PLANELLA, alguacil real (27).

b) El Canciller y el Vicecanciller

Sabemos que el obispo de Vic, Cosme MONTSERRAT, fue canciller del Principado, aunque no tengamos, del momento, documento que lo confirme. Este personaje continuó manteniendo el cargo con don Pedro de Portugal y Renato de Anjou (28).

El cargo de vicecanciller lo desempeñó Gaspar VILANA, escribano que fue del Consell barcelonés. Vilana fue nombrado interínamente para el cargo el 20 de diciembre de 1462 , como nos indica el siguiente texto:

"Lo dit die se tench Consell de Cent, e fou possat en Vicecanciller micer Gaspar VILANA, advocat ordinari de le present ciutat" (29).

Un día después, Juan de Beaumont, escribió a Enrique IV comunicándole el nombramiento, pues, alegaba, no odía retrasar más los asuntos de justicia, incitándole, al mismo tiempo, para que lo confirmase (30).

Otra carta con idéntico contenido fue remitida a don Juan Ximéniz de Arevalo (31).

El 1 de marzo de 1463, al frente del cargo, Vilana, lo simultaneaba con el que tenía en el Consell de la Ciudad. Una vez recibida la confirmación real, nuestro personaje, abandonó sus funciones municipales y se dedicó exclusivamente a la Cancillería. Por ello, el 29 de marzo, el Consell le nombró sucesor:

"Lo dit dia fou provehit per los honorables consellers e Concell de XXXII, micer Arnau Mas, de la advocació ordinaria de la ciutat per tant com micer Gaspar Vilana, qui obtenía lo dit offici és estat provehit vicecanciller del senyor rey" (32).

Vilana cuidó de las citaciones judiciales a la Curia (33), de los actos de justicia, de la revisión de los documentos de la Cancillería, etc.

(27) Id., docs. 1764, 1844, 1872, 1896, 1897, 1919 y 1933.

(28) A.M. ARAGó-J. TRENGHS, Las cancillerías, citado.

(29) Dietari, pág. 424.

(30) J. SOBREQUES, doc. 90.

(31) Id, doc. 91 .

(32) Dietari, pág. 428. y J. SOBREQUES, doc. 586.

(33) Texto del 19 de septiembre de I463. J. SOBREQUÉS, doc. 1874. 
Como vicecanciller, en fecha 16 de mayo, suplicó de su homónimo pontificio una canonjía en Barcelona para su hijo Jaume, que era clérigo (34).

\section{c) El protonotario}

El 11 de noviembre de 1462, Roderic VIDAL, fue nombrado protonotario del Principado. Este personaje ya conocía el cargo pues ya lo había desempeñado con el infante Carlos (35).

Tenía entre sus cometidos: cobro del derecho del sello, de que debía pagar a los secretarios, escribanos, petitionarii, archivero y maceros, según consta en un texto del 28 de mayo de 1463(36). También debía examinar y admitir a los escribanos de la casa real como consta en otro documento del 13 de octubre (37).

El protonotario desempeñó también, durante este breve reinado, el cargo de embajador en Castilla (38). A finales de noviembre, ante la problemática planteada por los funcionarios foráneos de Cataluña, tuvo que demostrar documentalmente que su abuelo era originario del reino, como exigían las ordenanzas y constituciones (39).

En otros documentos regestados por Sobrequés recibe varias cantidades de dinero correspondientes a embargos efectuados a enemigos del Principado (40).

\section{d) Los secretarios}

Como mandaba la pramática de Alfonso V (41), también durante la lugartenencia de Juan de Beaumont, Cataluña y su rey, tuvieron dos secretarios:

1. Jaume PELLICER, quien, además, fue enviado como embajador a Génova (42), y

2. Francesc TORRO, ciudadado de Barcelona (43), quien también desempeñó varias misiones diplomáticas (44).

(34) J. SOBREQUÉS, doc. 1115.

(35) Id., doc. 1 .

(36) Id., doc. 1203.

(37) Id., doc. 2008.

(38) Id., docs. 2025, 2091 y 2092.

(39) Id., doc. 1927.

(40) Id., doc. 1631 .

(41) F. SEVILLANO, pág. 198.

(42) J. SOBREQUÉS, docs. $654,655,661,2080-82$.

(43) Id., doc. 1194.

(44) Id., doc. 1368. 
Las funciones de los secretarios son idénticas a las conocidas en otras cancillerías precedentes y se adaptan a las decretadas por las Ordinacions.

\section{e) Escribanos de manamet}

Los escribamos de manament cuidaron de la puesta en limpio de determinados tipos de documentos. Fueron seis de modo fijo y alguno más de ocasional.

Por su labor en la escribanía cobraban de lo recaudado del derecho de sello, a razón de 4 sueldos diarios. Además de los mismos, anualmente, recibían otros 300 para vestido y calzado (45). Fueron escribanos del monarca;
1. Joan BERNAT (45).
2. Joan PUJOL (46).
3. Joan MASSO (47).
4. Miquel BRU (48).
5. Joan SALLENT (49).
6. Pere PUIG (50) y
7. Pau VIDA (51).

A veces, estos escribanos, cuidaron también del registro de los documentos (52).

\section{f) Escribanos de registro}

De los escribanos de registro del período sólo hemos localizado a Lluis CUBELLS (53).

Otros escribanos de Cancilleria, no sabemos si ocasionales o de registro, fueron:

1. Pere ROCA (54).

2. Francesc ROCA (55).

3. Pere PUIGGROS (56) y

(45) Id., doc. 1203.

(46) Ibid.

(47) Ibid.

(48) Id., doc. 1455.

(49) Id., doc. 2008.

(50) Ibid.

(5I) Id., docs. 1203, 1963, 2102 y 2137.

(52) F. SEVILLANO, ob. cit., pág.

(53) Id., doc. 1203.

(54) J. SORREQUÉS, doc. 806 .

(55) Id., doc. 1537.

(56) Id., docs. 310,311 y 1127. 


\section{Jaume OLMS (57). \\ g) Petitionarii}

Los petitionarii fueron los encargados de recibir las peticiones o súplicas presentadas a la Cancillería. También fueron escribanos. Hemos localizado a los siguientes:

1. Pau VIDA (58).

2. Pere SASALA (59).

Ambos eran notarios. El primero escribió una composición por la que recibió de salario 17 libras, 6 sueldos y 9 dineros $(60)$ y un pleito por el que cobró 60 sueldos (61).

El segundo, que se titula también escribano real, escribió dos procesos, cobrando por el primero 18 libras (62) y por el segundo, dos libras, un sueldo y tres dineros (63).

\section{h) Archivero}

Durante el período que nos ocupa continuó cuidando del archivo real, el archivero precedente, Juan GARCIA, cargo que mantendrá durante varios años (64).

\section{i) Porteros y alguaciles}

Los porteros cuidaron además de sus funciones de vigilancia del palacio real, de la cancillería, de la audiencia, etc., de llevar cartas y otros documentos por Barcelona, conducir presos, etc. Hemos localizado a los siguientes:

1. Antoni CARBONELL, alguacil (65).

2. Gil d'ESTAP, macero (66).

3. Joan de NOGUERA, alguacil (67).

4. Martí d'ORNA, macero (68).

5. Ramón de PLANELLA, alguacil (69).

(57) Id., docs. 2306-2307.

(58) Nota 51 .

(59) J. SOBREQUÉS, docs. 1203 y 2117.

(60) Id., doc. 1193.

(61) Id., doc. 2102.

(62) Id., doc. 2117.

(63) Id., doc. 2137.

(64) Id., doc. 1203. Sobre sus funciones vêase el trabajo de A.M. Aragó.

(65) Id., doc. 545.

(66) Id., doc. 1203. Lo era de la audiencia.

(67) Id., doc. 204.

(68) Id., doc. 1203. Lo era de la Audencia.

(69) Nota 27. 
6. Hug de PUIGPARDINES, alguacil (70).

7. Simó ROS, alguacil (71).

8. Antoni SAGARRA, portero real y alguacil (72).

9. Joan SALAMO, alguacil (73).

10. Bartomeu SAVILA, portero (74).

11. Arnau de VILADEMANY, alguacil (75).

\section{j) Correos y mensajeros.}

Los correos se encargaron de llevar los documentos de la Cancillería por los distintos pueblos, ciudades y personajes del Principado. Los segundos cuidaron de los textos diplomáticos, de relaciones con otros estados, con altros dignatarios, de efectuar y llevar tratados:

1. Joan CASTELL, correo (76).

2. Pere LIDON, correo (77).

3. Bernat de CLOTES, notario, mensajero (78).

4. Baltasar de QUERALT (79).

5. Joan MARTORELL, capitán de caravela, mensajero (80).

6. Juan VAZQUEZ (81).

7. Bernat CASSERRA (82).

8. Joan de GUALBES ( 837 .

9. Martí MAYA (84).

10. Jaume ELIES (85).

11. Mateu Joan de BERGA (86).

(70) J. SOBREQUES, docs. 1766, 1814, 1829, 1895, 1944 y 2023.

(71) Id., doc. 1571.

(72) Id., docs. 834, 1371, 1213, 1601, 2146, 2155, 2175, 2192 y 2198

(73) Id., docs. 1878, 1913.

(74) Id., doc. 600.

(75) Id., docs. 934, 970-1, 986, 1058, 1120, 1171-1, 1185, 1245, 1641 у 2256.

(76) Id., doc. 89.

(77) Id, , doc. 1815 .

(78) Id., doc. 202.

(79) Id., doc. 323 y 811 . Mensajero del rey.

(80) Id., docs. 824 y 827 .

(81) Id., docs. 2034-37, 2060, 2092 y 2161 . Era enviado del rey castellano.

(82) Id., docs. 153 y 171 . Era escribano apostólico de la diócesis de la Seu de Urgell.

(83) Id., doc. 1349.

(84) Id., docs. 16, 17, 1391, 1393, 1672 y 1673. Era navarro.

(85) Id., doc. 687.

(86) Id., docs., 92, 149, 229. Era embajador. 


\section{LA TESORERIA REAL}

De los oficiales encargados de los asuntos económicos conocemos al tesorero mayor, Guillem de SETANTI, quien el 21 de enero de 1463, fue nombrado provisionalmente para el cargo (87), en espera que el mismo fuera confirmado por el monarca, según consta en súplica del 30 de enero efectuada por Juan Ximénes de Arevalo (88).

Setantí cuidó del pago a los oficiales reales extraños a la Cancellería (89), para lo cual se servía de las cantidades incautadas a los rebeldes (90) y del cobro de las distintas multas (91).

A sus órdenes tuvo un lugarteniente, cargo que desempeó Joan de MONTREAL (92), quien, anteriormente, ya había desempeñado el cometido con el infante Carlos (93) y un maestre racional, del que sus funciones tampoco variaron. Este último cargo lo desempeñó Francesc DESVALL (94).

\section{LA AUDIENCIA Y SUS FUNCIOARIOS}

Los documentos de tipo judicial fueron expedidos por la audiencia. De la misma hemos localizado a varios personajes:

1. Damià MONTSERRAT, juez (95).

2. Lluis TORRENT, juez (96).

3. Antoni RIERA, procurador del fisco (97).

4. Berenguer OLLER, procurador del fisco (98).

5. Joan ROS, abogado del fisco (99).

6. Pere SABARTES, doctor en Leyes (100).

(87) Id., doc. 326.

(88) Id., doc. 394.

(89) Id., docs. 467, 870,873, etc.

(90) Id., doc. 1935, etc.

(91) Id., doc. 674.

(92) Id., doc. 589.

(93) Ibid.

(94) Id., doc. 431.

(95) Id., doc. 636.

(96) Ibid.

(97) Id., docs. 1130, 2307, 2310.

(98) Id., doc. 395.

(99) Id., docs. 2266. 2309.

(100) Id., doc. 1189. 
7. M. CASES (101).

8. G. GUARDIOLA (102).

Esta dependencia estuvo ligada a la Tesorería y en ella sólo hemos incluído a los personajes principales, prescindiendo de sus subordinados en las principales ciudades y villas.

\section{OTROS ESCRIBANOS}

Incluimos en este apartado a otros escribanos de fuera de Barcelona quienes dependieron directa o indirectamente de la monarquía o de los estamentos eclesiásticos y civiles de Cataluña:

1. Francesc GOSSET, doctor en Leyes de la oficialía del obispo de Barcelona (103).

2. Bernat CASSERA, escribano apostólico de la Cuira de Urgell (104).

3. Andreu de PLANES, notario y escribano del obispado de Vic (105).

No damos lista de los notarios aparecidos en los documentos ya que los de fuera de la Cancillería pasan del medio centenar (106) y ello se aparta de nuestro estudio.

\section{LOS REGISTROS Y LOS DOCUMENTOS}

Los registros y documentos de Enrique I de Cataluña y IV de Castilla han sido analizados por Sobrequés. Ellos presentan las mismas notas marginales que los de los reyes legítimos y ello puede verse tanto en las notas de sellado y registro, como en las siguientes: Non habuit effectum» (107); "Vidit Thomas Mieresp (108), «Fuit duplicata" (109), etc.

(101) Id., doc. 1198.

(102) Id., docs. 2202 y 2203.

(103) Id., docs. 135, 411, 1452, 1837.

(104) Id., docs. 153, 171 .

(105) Id., doc. 913.

(106) J. SOBREQUES, Catálogo, en su indice de personajes.

(107) Id., doc. 1966.

(108) Id., varios docs.

(109) J. SOBREQUES, Poblet, 28. 


\section{CONCLUSION}

Como habrá podido comprobarse, la Cancillería del primer monarca intruso no presenta ningún tipo de diferencia con la de los monarcas legítimos y ello es debido a que, en la continuidad de funciones, buscaban la legalidad del cambio. 